\title{
Using Colours to alter Consumer Behaviour and Product Success
}

\author{
Tom Page \\ Electronic Product Design in Department Design and Technology \\ Loughborough University, Loughborough, Leicestershire, United Kingdom \\ Gisli Thorsteinsson \\ Design and Craft Education Department \\ University of Iceland, Stakkahlid, Reykjavik, Iceland \\ Joong Gyu Ha* \\ Industrial Design in Fine Art Education Department \\ Gyeongsang National University, Jinju, Gyeongnam, Korea
}

\begin{abstract}
t
This paper aims to present colour theories and show how they can be used to explain consumer's preferences of some products over others. It will, furthermore, attempt to link these theories to the design industry and look at how colour associations determine product success. Due to associative learning and personal preference, the colours of objects can cause consumers to either favour or dislike products over those with identical functions and efficiency. Age and gender affect the preferred colour choices of the individual, making some products more popular to particular groups of potential consumers. Designers can utilise colour theories to ensure that they use the most appropriate colour schemes to maximise and appeal to their targeted market successfully. A survey was conducted with 100 participants. It demonstrates the associative links between colours, emotions and product categories. It can be shown that the colour of an object can contribute to its success or failure in the market based on a number of different criteria. The design must use colour confidently to evoke certain emotions or connotations and must be carried out appropriately. The designer also has to consider whom it is that be viewing it and making the decision of preference.
\end{abstract}

Keywords: colour theories, consumer's preferences, associative learning, design industry, emotional responses, psychology, product preference gender, age, associative learning.

\section{INSTRUCTION}

Colour is an important aspect of communication and design in all areas of the industry. Certain people may be more aware and colour literate than others, however, in some way there is the possibility that the colours we see around us can affect how we behave [1]

Colour theories have been used for many years in the visual arts in order to describe the best techniques of colour mixing to provide the most impacting and outstanding images [2]. They are important considerations for artists and visual experts and have been well documented [3], [4]. These theories however only make connections between how each can be used to enhance the next. Colour perception theories

\footnotetext{
* Corresponding author. E-mail : hajoonggyu@gnu.ac.kr Manuscript received Oct. 31, 2011 ; accepted Jan.30, 2012
}

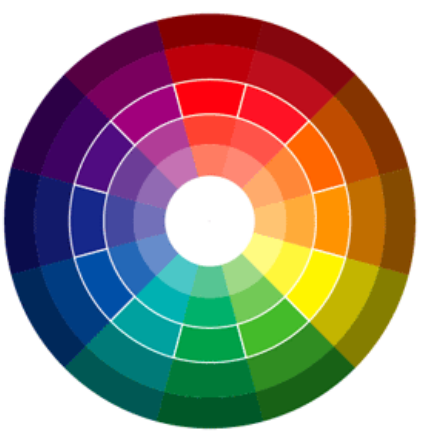

Fig. 1. Color wheel

go further and ask why do we as humans see colour? They aim to explain the inner workings of the eye and describe the processes necessary for a person to look at an object and see 
that it is blue and how bright it may be.

Once again this has been well documented and it is a wellestablished theory with few variations but many authors. The connections made in these theories are about illumination, colour brightness and hues, and how well they are each picked up and processed by the eye to inform the brain.

The paper discusses various theories on colour use and association and apply them to the design of consumer products [5], [6], [7]. It shows the connection between colour choice and target market, and how associative learning can affect the consumer's perception of these choices as past psychology journals demonstrate a strong contrast within these groups when questioned about their preferences and favorite colours [8].

The work based on literary findings and a survey that was carried out which questions shoppers about their colour preferences and how aware they are of the colours used in branding and logos around them. The results were collected from two different shopping centres and cover a wide range of ages. It also questions them on colour association and the meanings of some colours. The aim is to show a link between why buyers prefer particular colour choices and their previous experiences with the colours.

\section{COLOUR THEORIES}

As Enid Verity states in Colour Observed (1980), 'In one way or another everyone is interested in colour'. A true statement as whether we are aware or not, every colour has the possible ability to affect our opinions and behaviour in everyday situations [9]. There are a range of different types of theories relating to the subject of colour, however each focus on a different area of interest.

'The psychological factor of colour has been neglected; yet it is the psychological factor that is most important in our daily lives [2]. At a time before colour psychology was truly considered relevant Louis Cheskin suggests the subconscious and psychological impact colours may have. He believed that there was a significance to colour in everyday situations that everyone has the ability to react to it. Although perception theories explain how the colour reaches the brain, psychological theories can explain why we are prone to react in certain ways [10]. Colour is, after all, all around us; 'There is no such thing as an absence of colour. Colour is always present- good or bad colour, but colour nonetheless' [2].

Whether the colour is good or bad may not be decided purely on how it compliments the surrounding but also how it may make people feel. As he suggests, it is important to understand that colour is everywhere and the consumer is constantly open to new experiences to add more emotion to the meaning of certain colours [11]. introduce red signage to an environment. It has the influential power on our conscience to make an area appear potentially hazardous and dangerous. Although the danger may not be apparent to the viewer, the colour red is so powerful that people will automatically become more aware [12].

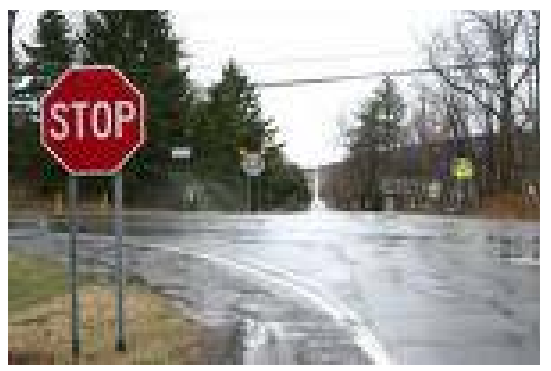

Fig. 2. Red signage in environment

How each individual person perceives a colour may cause it to have either a negative or a positive impact on their moods [13]. One colour may enhance a person's happy persona where another may encourage them to feel more sombre or downhearted. Birren discusses the emotional reactions to different colours in, 'Colour and Human responses' (1978). He suggests that warm hues increase stimulation and muscle tension and cool colours relax them. This demonstrates a different reaction to each side of the colour wheel, where complimentary colours give way to contrasting emotional responses.

An experiment carried out to test this theory in which a number of subjects where moved through rooms in which the walls were painted different colours. Bright rooms and warm colours gave happy, cheerful responses [14].

Angela Wright specialises in how human behaviour can be linked to colour patterns and its appropriate use in corporate branding. The London based company 'Colour affects' was founded in 1985 to help companies enhance their image and use appropriate combinations of colours to appeal to the necessary markets. There is always a risk that a company is not being taken seriously due to its branding. An interesting line of investigation that she has pursued is a small case study on the colours of petrol service stations in the U.K and how the colour choices affect their public image. The companies analysed were Texaco, Shell and BP. All three provide the same public service within the same working environment, however have three very different perceived personalities that can be explained their colour schemes. In Texaco, Wright explains, has a mainly masculine and car enthusiast market which can be connected to the intimidating and sometimes 'menacing' colour scheme of bright red, black and white.

It is therefore understandable that BP with its bright, optimistic and welcoming spring colour scheme is a more popular with female and more youthful motorists who may be more not sure of themselves [15].

A simple example of the impacts colour would be to 

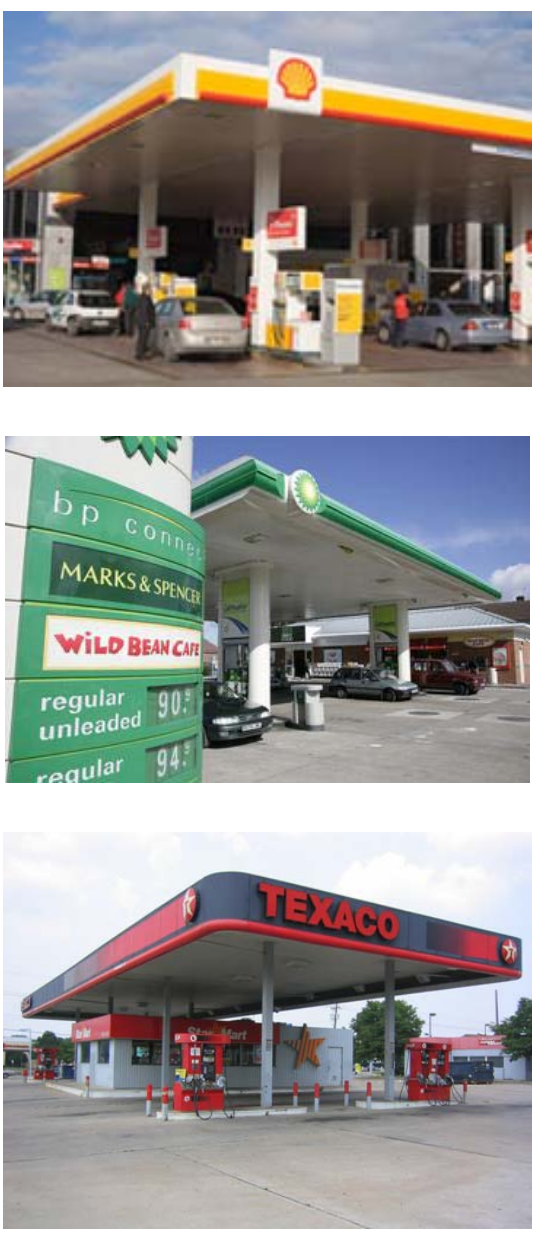

Fig. 3. The color scheme of petrol service stations has the ability to give the consumers different expected experiences at each location.

'The implications of using colour psychology across the commercial world to influence people's unconscious responses and purchasing decisions are enormous, and cover packaging, interiors, advertising and promotional material of all kinds' [16].

The Luscher Test, designed in the 1940s by Swiss psychologist Max Luscher, uses colour swatches to interpret a subject personality and character. The individual is asked to place 8 coloured pieces of card in a line in order of preference. The colours all have pre-determined meanings or symbolism. The cards and emotional meanings connected are then analysed to give feedback to the subject about their personality traits. For example, blue is connected with tranquillity, tenderness and love, whereas red holds the meanings of desire, domination and sexuality [17], [18].

Luscher's colour preference personality test is a well established and respected practiced and features as a regular argument in favour of the emotional ties to colour preference. Consumers may be more inclined to purchase products that reflect the colours of their personality and therefore the choice is a personality informed preference. Although the test is for an individual's personality, Luscher was able to see a trend in the preference of blue with European subjects [17].

\section{EMPIRICAL INVESTIGATIONS}

A survey was undertaken to investigate how aware the 'everyday shopper' is of the connections in colour, emotion and product preference. It interest was to study whether the consumer makes conscious choices due to the previously discussed associative learning theories, and to question them directly on their awareness of colour.

Previous experiments in colour used a range of subjects in controlled situations and environments to test their preferences of a range of swatches (Luscher as cited in Gage). As this study is research to link colour directly to product preference and success it was of best interest to contact consumers directly in their own environment, i.e. shopping centres.

The aim was to ask a range of questions that would cover the areas of colour association and awareness and to also test the literary theories on associative colour/product connections. To show that repetitive exposure to certain colour/product associations would teach shoppers a connection [19].

\section{METHODS OF DATA COLLECTION}

A total of 100 surveys were conducted in 2 different shopping centres with an equal amount of men and women participating. Keeping an equal number would help to remove any issues of gender based preference as discussed previously [9].

The subjects were chosen by random from the street based on their age and who was able to stop and spare the time. The subjects were all of 16 years or older. This is because there is content relating branding, and the subjects should be responsible for their own awareness of this subject and purchasing habits.

The questions were read aloud to the subject and when necessary the images ere shown and the subject asked to point at their chosen answer. The questionnaire consisted of 13 questions and when piloted was discovered to be of an agreeable length to keep the subject interested and focussed for the time necessary.

\section{FINDINGS}

The survey proved an effective method of supporting the theories of colour and product relations. By asking the consumers themselves about their colour awareness interesting results were obtained to explain how easily the 
associations could be made between emotions, product types and branding with colour.

Repetitive colour symbolism affects the consumer to make instant associative connections and this was very successfully demonstrated in the word-colour association question. The top three colour responses for each word can successfully be seen in products and branding relating to the word. I.e. natural and gardening products coloured green (nature) or HIFIs, DVDs and televisions being predominantly back, or silver (technology).

The consumer is also prone to make colour preference decisions when presented with variations that relate to certain product stereotypes of expected colour schemes. The decisions are based on the repetitive exposure of what companies believe to be appropriate product category colours and therefore consumers then associate these with good performance and reliable function.

The average consumer also demonstrated effective ability to recognise famous brands based on the form and colours they were presented with. The difficulty came when choosing the correct coloration from a range. By using a brighter colour on one of the Pepsi logo variations, the study supported the theory of colour memory. The idea that the colour humans recall from memory has a tendency to be brighter and more saturated. Although the colours were in opposite positions a large amount of participants chose the brighter variant.

\section{DISCUSSION AND CONCLUSIONS}

This study was conducted with the aim to answer a number of questions connecting the colour choice of a product to its success in the market. The questions asked if it is possible that a products colour is used as a means to encourage consumer choices and affect their behaviour, and if the coloration could ultimately decide the success or failure of a product. These were believed to be fundamental questions that should be explored to enhance our understanding of product preference and further our knowledge in the success of particular products over others.

It has been shown through literary support and empirical evidence that colour can be a means in which consumers are to base their preferences on over the competition. There have been a number of elements discussed to support reasoning that through psychological, associative and emotional influences a consumer will have different feelings towards a product's colour. Emotional and psychological influences will cause a buyer to choose a product that enhances how they are feeling or a mood they wish to express with the product in question. The colour whether warm or cold, dark or light, will have the ability to express a meaning or symbolism the individual is expecting. If the designer gets these expectations the wrong way around, i.e. a cheerful, playful product with a dark or depressing exterior, the buyer will purchase an alternative brand with the correct coloration.

Whether the consumer feels the product has an appropriate colour scheme can be closely linked to associative teachings in the individual's own lifestyle and experiences, or through repetitive exposure to associations made by company advertising or branding. Colour conventions for particular product categories will also teach the consumer a link to which colours they feel displays reliable and expected performance.

The study has also shown empirical evidence of the different reactions to colours between male and females and therefore the explanation of why different coloured products relate to the different sexes. Women are prone to make the choice of a light coloured product than the dark colours of male preferences. Designers can use this to their advantage to ensure their product is targeting and relating to the correct sex [20].

It can be said that the colour of an object can contribute to its success or failure in the market based on a number of different criteria. The design must use colour confidently to evoke certain emotions or connotations. It must be carried out appropriately and to always consider whom it is that be viewing it and making the decision of preference.

\section{REFERENCES}

[1] D. Russell, Colour in industrial design, The Design Council London, 1991.

[2] L. Cheskin, Colours and what they can do, Blandford Press Ltd, London, 1951.

[3] F. Jackson, "Philosophising about colour. In Color Perception”, S. Davies, Vancouver Studies in Cognitive Science, Vol. 9, Oxford University Press, 2000, pp. $152-162$.

[4] P. Zelinski and M.P. Fisher, Colour for designers and artists, The Herbert Press London, 1989.

[5] T.A. Shrimp, "Neo-Pavlovian conditioning and it implications for consumer theory and research", in T.S. Robertson, H.H. Kassarjian (Eds), Handbook of Consumer Behaviour, Prentice-Hall, New York, 1991.

[6] R.P. Heath, The wonderful world of colour, Marketing tools,

1997. http://www.demographics.com/publications/mt/9 710_mt?mt971022.tm.

[7] S.G. Beatty, "H-P goes in for a marketing makeover", Wall Street Journal, 1997.

[8] J. Davidoff, Cognition through color, The MIT Press, Cambridge, MA, 1991.

[9] R.F. Wilson, Colour in Industry today; A practical book on the functional use of colour, Unwin Brothers limited, Woking and London, 1960.

[10] D. Steven, Colour perception: philosophical, psychological artistic and computational perspectives, Oxford University Press, New York, 2000.

[11] W. Sargant, The enjoyment and use of colour, Dover 
Publications, Inc, New York, 1964.

[12] A.J. Elliot, M.A. Maier, A.C. Moller, R. Friedman, \& J. Meinhardt, "Color and psychological functioning: The effect of red on performance attainment", Journal of Experimental Psychology: General, Vol. 136, No. 1, (2007), pp. 154-168.

[13] M. Hemphill, "A note on adults colour-emotion associations”, Journal of Genetic Psychology, Vol. 157, (1996), p. 275.

[14] F. Birren, Color and human responses. Aspects of light and colour bearing on the reactions of living things and the welfare of human beings, Van Nostrand Reinhold Limited, New York, 1978.

[15] A. Wright, Beginners guide to colour psychology, Kyle Cathie Ltd, London, 1995.

[16] A. Wright, Colour psychology, 2008. Available at http://www.colour-affects.co.uk. (Accessed 1 March 2010).

[17] J. Gage, Colour and meaning; Art, Science and symbolism, Thames and Hudson, London, 1992.

[18] J. Albers, Interaction of colour, Yale University Press, London, 1963.

[19] R.P. Grossman, J.Z. Wisenblit, "What we know about consumer's color choices”, Journal of Marketing Practice; Applied Marketing Science, 1999, pp.78-88.

[20] D. Funk and N.O. Ndubisi, "Colour and product choice: a study of gender roles”, Journal of Management research news, 2006, pp. 41-52.

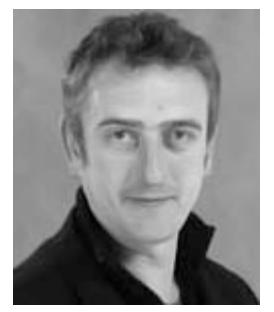

\section{Tom Page}

He obtained his BSc. and M.Phil in Engineering Design from Napier University, in 1988 and 1992. He obtained a PhD from the University of Hertfordshire in 2002. He is an external examiner on Engineering and Manufacturing programmes at Sheffield Halllam University. He is a visiting scholar at Iceland University and the University of Lapland in Finland and has been an external examiner on undergraduate fields in Product Design and Manufacturing Engineering at the University of East London. (2008 to present) He is a lecturer in Electronic Product Design in Department Design and Technology at Loughborough University, 2003 to present. Among his main research areas are in the research and development of computer applications for design and technology education, logistics and supply chain management and electronic product design.

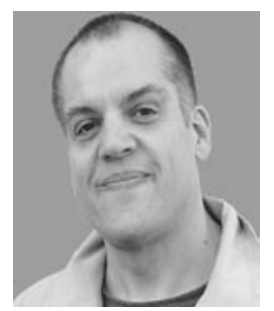

\section{Gisli Thorsteinsson}

He obtained his B.Ed. in 1980, in Design and Craft Education from the University of Iceland and his PhD. from Loughborough University, Leicestershire, England in 2010. Gisli has been the Chairman of the Association of Icelandic Industrial Arts Teachers since 1995. From 2000 he has been on the Board of
'Nordfo', the Pan Scandinavian co-operative researching Art and Design projects in Scandinavia. Gisli has been an Assistant Professor at the University of Iceland, since 1996, in the Department of Design and Craft Education. His main research focus has been on exploring the values of using Virtual Reality Learning Environment for supporting the development of ideation skills in students, in Icelandic schools.

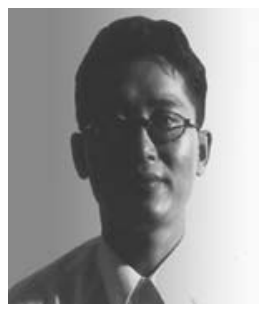

\section{Joong Gyu, Ha}

He obtained his B.A. and M.A. in Industrial Design from Hong-Ik University, Seoul, Korea. He was associated with BioDesign Innovation Centre in Korea as CEO from 2003 to 2005 and was a visiting scholar in Sustainable Design in the Department of Design and Technology at Loughborough University, Leicestershire, England. He has won the 'Best Design Award' from the 2009 Exhibition of Invited International Designers, 16 countries around the world's representative industrial and environmental designers participating in Busan, Korea. He is a professor of Industrial Design in the Department of Art Education at Gyeongsang National University, Korea, from 1988 to present. His research interests include the sustainable product design education for industrial designers and environmental designers. 